\title{
A Qualidade de Vida no Trabalho da População de uma Pequena Cidade: um Estudo em Dom Pedrito/RS
}

\author{
The Quality of Life in the Work of the Population of a Small Town: a Study in Dom \\ Pedrito/RS
}

La calidad de Vida en el Trabajo de la Población de una Pequeña Ciudad: un Estudio en Don Pedrito/RS

Julia da Cunha Stoelben
Discente de Tecnologia em Agronegócio: UNIPAMPA/RS
juliastoelben@ @otmail.com
http://lattes.cnpq.br/8358011627953044
https://orcid.org/0000-0002-6615-5430
Gustavo da Rosa Borges ${ }^{1}$
Docente da UNIPAMPA/RS
gustavodarosaborges@gmail.com
http://lattes.cnpq.br/5162584966597575
https://orcid.org/0000-0002-9869-376X
Universidade Federal do Pampa, UNIPAMPA, Brasil ${ }^{1}$

Artigo recebido em 27.06.2019. Última versão recebida em 29.06.2019. Aprovado em 30.06.2019. 


\title{
Resumo
}

Há algum tempo as empresas têm percebido a importância dos colaboradores se sentirem bem no ambiente de trabalho, sendo que a preocupação com a sua qualidade de vida vêm cada vez mais ganhando espaço. Desta forma, diversos estudos buscaram medir a Qualidade de Vida no Trabalho (QVT); entretanto, poucos fizeram uma análise em pessoas residentes em cidades pequenas que trabalham nas mais diversas empresas e segmentos. Assim sendo, o presente artigo tem por objetivo medir o nível de QVT de trabalhadores de Dom Pedrito/RS. Por meio de uma pesquisa quantitativa e descritiva, contando com a participação de 127 pessoas, descobriu-se de forma geral, o nível de QVT da população é mediano. Os investigados consideram a não existência de preconceito e a motivação para trabalhar os principais itens positivos; dentre os mais negativos, destacam-se a falta de instrumentos para a prática do trabalho e o fato de haver mudança na rotina das pessoas. Por fim, descobriu-se que não existem diferenças de níveis de QVT de acordo com o gênero e a faixa-etária, dando a entender, que a QVT é uma percepção que não depende do perfil das pessoas.

Palavras-chave: Qualidade de Vida. Trabalho. Cidades Pequenas.

\section{The Quality of Life in the Work of the Population of a Small Town: a Study in Dom Pedrito/RS}

\begin{abstract}
For some time, companies have realized the importance of employees feel good in the workplace, and concern for their quality of life is increasingly gaining space. Thus, several studies sought to measure Quality of Life at Work (QWL); however, few have done an analysis on people residing in small towns that work in the most diverse companies and segments. Therefore, the objective of this article is to measure the QoL level of workers at Dom Pedrito / RS. Through quantitative and descriptive research, with the participation of 127 people, it was generally found that the level of QWL of the population is medium. The investigated ones considered the nonexistence of prejudice and the motivation to work the main positive items; among the most negative, are the lack of instruments for the practice of work and the fact that there is a change in the routine of the people. Finally, it was found that there are no differences in QoL levels according to gender and age, implying that QWL is a perception that does not depend on the profile of the people.
\end{abstract}

Keywords: Quality of life. Job. Small Cities.

\section{La calidad de Vida en el Trabajo de la Población de una Pequeña Ciudad: un Estudio en Don Pedrito/RS}

\section{Resumen}

Desde hace algún tiempo las empresas han percibido la importancia de que los empleados se sienten bien en el ambiente de trabajo, siendo que la preocupación por su calidad de vida viene cada vez más ganando espacio. De esta forma, diversos estudios buscaron medir la Calidad de Vida en el Trabajo (QVT); sin embargo, pocos hicieron un análisis en personas residentes en ciudades pequeñas que trabajan en las más diversas empresas y segmentos. Así, el presente artículo tiene por objetivo medir el nivel de QVT de trabajadores de Don Pedrito / RS. Por medio de una encuesta cuantitativa y descriptiva, contando con la participación de 127 personas, se descubrió de forma general, el nivel de QVT de la población es mediano. 
Los investigadores consideran la no existencia de prejuicio y la motivación para trabajar los principales ítems positivos; entre los más negativos, se destacan la falta de instrumentos para la práctica del trabajo y el hecho de haber cambio en la rutina de las personas. Por último, se descubrió que no existen diferencias de niveles de QVT de acuerdo con el género y el grupo de edad, dando a entender, que la QVT es una percepción que no depende del perfil de las personas.

Palabras clave: Calidad de vida. Trabajo. Ciudades Pequeñas. 


\section{INTRODUÇÃO}

O mundo do trabalho vem passando por profundas transformações, o avanço da tecnologia e informações, com grandes aprimoramentos nos processos organizacionais trouxeram um aumento na preocupação com o indivíduo envolvido, como a falta de motivação e o estresse. Grande parte da vida das pessoas se passa dentro de empresa, trabalhando (Carvalho, Martins, Lúcio, \& Papandréa, 2013), com isso percebe-se a grande a importância que o trabalho exerce sobre a vida das pessoas. Há, contudo, uma nítida contradição: muitas pessoas o têm como um fardo, como algo difícil, que só é realizado por uma necessidade financeira. Para outros, o trabalho é interpretado com meio para crescimento pessoal, como sentido para a vida, definidor de responsabilidade e identidade pessoal.

Para muitos, a própria rotina e distração que o trabalho promove acaba por caracterizá-lo como um simples meio de sobrevivência, o que desconsidera as expectativas, os sentimentos, a motivação e a qualidade de vida dos colaboradores nas organizações, e acaba refletindo negativamente em sua autoestima e em seu desempenho na instituição empregadora (Miranda, 2009).

A Qualidade de Vida no Trabalho (QVT) tem ocupado um espaço cada vez maior dentro das instituições (Pereira, 2011). Ela envolve o lugar e esfera social, como as pessoas que ali estão, devendo-se avaliar desde os posicionamentos dos equipamentos até o relacionamento interpessoal dos funcionários, observando como esses profissionais estão estabelecidos no ambiente da organização, destacando sempre a QVT (Limongi-França, 1996).

Pretende-se assim, analisar a QVT, o estresse e a sobrecarga no ambiente de trabalho, mostrando sua importância para o indivíduo, que trabalha muitas vezes exercendo várias atividades, e para as empresas que perdem em qualidade, produtividade e eficiência; as empresas que aderem ao conceito "qualidade de vida no trabalho", geram informações que minimizam a fadiga, a exaustão e os problemas de saúde, fatores esses ocasionados pela rotina repetitiva em excesso, começam a enxergar o ser humano como um caminho para o seu desenvolvimento e crescimento. Segundo Liberato, Ballstaedt e Abril (2013), o estresse é essencialmente um grau de desgaste no corpo e da mente, que pode atingir níveis degenerativos, sensação de estar nervoso, agitado, irritado ou debilitado. Ribeiro (2015) complementa que estudos recentes demonstram que um trabalho que não for considerado gerador de bem-estar trará mais prejuízos do que benefícios, acarretando em falta de atenção, baixa produtividade e alta rotatividade, a sensação de bem-estar no trabalho está ligada a um clima organizacional positivo, possibilidade de crescimento na carreira, bom relacionamento com os colegas e em se ter um bom chefe.

Com a grande concorrência do atual mundo globalizado, as organizações acabam se preocupando mais com o lucro e a colocação no mercado, o que exige mais de seus colaboradores: horas e altos índices de resultados; estas não promovem a saúde física e mental de seus colaboradores, através dessa dificuldade a busca pela QVT procura desenvolver um ambiente de trabalho adequado para o colaborador e com isso trazer melhores resultados através de aumentos na produção, produtividade e de um maior comprometimento com a missão da empresa (Ribeiro, 2015). A motivação nas empresas são todos e quaisquer incentivos ou recompensas que o colaborador recebe para conseguir atingir um determinado objetivo laboral, como exemplo: remuneração de acordo com os resultados, autogestão nos grupos de trabalho, enriquecimento do trabalho, dentre outros (Miranda, 2009).

UFAMBR, Manaus, v. 1, n.1, art. 2, pp. 18-35, janeiro-junho, 2019 http://www.periodicos.ufam.edu.br/ufambr 
Entretanto, existem alguns fatores externos que influenciam na qualidade de vida das pessoas (Nahas, 2006; Pereira, 2011), incluindo a QVT (Medeiros, 2002; Silva \& Lima, 2007; Ribeiro, 2015). Sobre este aspecto, Figueiredo (2008) esclarece que o ambiente da cidade influencia na Qualidade de Vida, especialmente em cidades pequenas, que tem uma peculiaridade singular. Indo ao encontro desta premissa, Vieira, Lacerta, Vierira e Seidl-DeMoura (2011) confirmam que pessoas que residem em cidades pequenas têm estilos de vida, objetivos e qualidade de vida diferentes das que residem em cidades maiores.

Por outro lado, observa-se a existência de poucos trabalhos que buscassem medir a QVT de pessoas que residem em pequenas cidades. A maioria dos trabalhos sobre QVT apresenta resultados em uma única empresa e pesquisam amostras em cidades maiores. Buscando preencher esta lacuna, este artigo tem por objetivo descobrir qual é o nível de QVT de trabalhadores de Dom Pedrito/RS. A escolha por Dom Pedrito justifica-se por ser uma cidade pequena e localizada no Sul do Brasil, sendo considerada uma cidade fronteiriça, o que torna este trabalho singular.

You (2018) destaca que cidades fronteiriças, as chamadas border cities, são cidades geralmente pequenas e médias, que possuem um fluxo de pessoas diferenciadas. Gao e Long (2014) destacam que estas cidades tendem a ter conflitos culturais. Portanto, como destacado, busca-se aqui, averiguar a QVT em uma destas cidades.

O presente artigo abordará no referencial teórico a qualidade de vida e QVT. Após, será apreciada a metodologia, os resultados e as considerações finais.

\section{REFERENCIAL TEÓRICO}

\subsection{Qualidade de Vida}

A QV ainda não foi bem conceituada e definida quanto às quais fatores a influenciam, no princípio pensava-se que era somente a remuneração e as conquistas profissionais que a afetam, mas com o passar do tempo novos fatores passaram a ser avaliados como grau de satisfação, satisfação pessoal, local de trabalho com condições adequadas, entre outros (Pereira, 2011).

Nahas (2006) sugere que para se ter uma boa QV é importante possuir uma alimentação saudável, realizar atividades físicas, cuidar da saúde de forma preventiva, procurar cultivar amizades e relacionamentos que lhe traga satisfação e controlar o estresse. Pereira (2011) estudando estes itens os resume ao bem estar de cada indivíduo, pois este é muito amplo e envolve desde satisfação com a vida familiar, recreação, espiritualidade, satisfação como o trabalho, oportunidades de promoção, colegas, etc., visto que nossas escolhas e decisões cotidianas, nosso estilo de vida têm afetado a maneira como vivemos e por quanto tempo vivemos.

De acordo com Minayo, Hartz e Buss (2000), a qualidade de vida tem sido igualada a satisfação encontrada na vida familiar, amorosa, social e ambiental; o termo é uma construção social com a marca da relatividade cultural, abrangendo muitos significados, que refletem conhecimentos, experiências e valores de indivíduos e coletividades. 
De acordo com Minayo, Hartz e Buss (2000), a qualidade de vida tem satisfação semelhante a encontrada na vida familiar e social; está ligada a relatividade cultural, que possui muitos significados, que refletem conhecimentos, experiências e valores de indivíduos e coletividades. As pessoas procuram nas empresas, além de salário, a possibilidades de aprendizagem e realização de seu potencial, reconhecimento, amizades e identificação com seu trabalho, e a empresa, busca empregados produtivos e comprometidos com os objetivos organizacionais, a fim de oferecer aos seus clientes produtos e serviços de qualidade, aperfeiçoar seus recursos produtivos e dar retorno aos acionistas (Da Silva; Furtado; Zanini, 2015).

A QV é uma busca de todos, e o trabalho talvez seja um dos mais influentes fatores que contribuem para a sua melhoria, pois a maior parte do tempo ativo é dispendido no local de trabalho e também é a partir deste que se obtém retorno financeiro, possibilitando a educação, o lazer e o conforto. Uma QV melhor faz os trabalhadores mais felizes proporcionando uma aproximação maior com o cliente, estando mais atentos às variáveis existentes nos produtos e desenvolvendo serviços e produtos mais qualificados, trazendo melhores benefícios as empresas (Gonçalves, 2005).

Cabe ressaltar que o trabalhador deve se identificar com a organização, trabalhando em equipe, e estas devem contribuir para a sociedade não somente com a geração de bens, mas também socialmente e culturalmente, com investimentos à valorização do potencial humano e sua capacitação. Como a QVT passou a fazer parte das rodas de conversas nas instituições, procurando informar-se mais sobre o assunto e através dos programas de qualidade de vida desenvolvidos nas organizações, estas procuram formas de encantar $\mathrm{o}$ funcionário $\mathrm{e}$ minimizar os possíveis conflitos (Pereira, 2011).

\subsubsection{Qualidade de Vida no Trabalho}

A corrente QVT teve seu princípio na década de 50 na Inglaterra, pelo psicólogo Eric Trist, que em conjunto com outros cientistas, efetuou pesquisas que buscavam compreender a relação existente entre pessoa, trabalho e instituição, considerando as condições que faziam as pessoas desempenharem bem suas funções e com isso diminuir o sofrimento da vida dos colaboradores, a partir da reforma das tarefas (Ribeiro, 2015).

Segundo Drucker (1997), o trabalho tem sido constituinte da identidade do sujeito ao longo de sua evolução, através do trabalho as pessoas podem transmitir seu conhecimento de forma inventiva e criadora, deixando o seu registro, e este está diretamente ligado a sua dignidade, portanto, este tem se evidenciado uma preocupação há muitos milênios, não somente pela manutenção financeira.

Após as diversos atividades de downsizing, reestruturação e reengenharia que marcaram a década de 90, no início deste século as pessoas passaram a trabalhar cada vez mais, e assim, a ter menos tempo para tomar com de si mesmo (Veiga, 2000).

Segundo Fernandes et al. (1996, p. 46) QVT é uma: 
gestão dinâmica porque as organizações e as pessoas mudam constantemente; e é contingencial porque depende da realidade de cada empresa no contexto em que está inserida. Além disso, pouco resolve atentar-se apenas para fatores físicos, pois aspectos sociológicos e psicológicos interferem igualmente na satisfação dos indivíduos em situação de trabalho; sem deixar de considerar os aspectos tecnológicos da organização do próprio trabalho que, em conjunto, afetam a cultura e interferem no clima organizacional com reflexos na produtividade e na satisfação dos empregados.

Da Silva, Furtado e Zanini (2015, p. 3) complementam que QVT:

é a forma pela qual se busca aplicar melhores condições para o desenvolvimento do ser humano, seja esta evolução social, mental e emocional. Além disso, a QVT se constitui em uma ferramenta importante para as organizações. Pois, ela proporciona maior participação por parte dos colaboradores, criando um ambiente de integração com superiores, com colegas de trabalho e com o próprio ambiente de trabalho, visando, principalmente, dois aspectos importantes que são o bem-estar do trabalhador e a eficácia organizacional.

Para da Silva Timossi, de Francisco, dos Santos Junior e de Paula Xavier (2010, p. 1):

Algumas empresas, os conceitos de satisfação pessoal no trabalho, de
qualidade pessoal e de valorização do capital humano passaram a estar
associados ao desenvolvimento da qualidade de serviços e produtos.
Atentando a isso, algumas organizações optam por investigar em
alguns fatores relacionados à saúde dos colaboradores, como: estilo de
vida, satisfação, qualidade de vida (QV), qualidade de vida no trabalho
(QVT), lazer e hábitos cotidianos.

Percebe-se que a QVT busca a harmonia entre as expectativas do indivíduo e da empresa, sempre buscando um melhor desenvolvimento humano e melhores resultados organizacionais (Santos 2012).

Para poder-se prestar um bom atendimento ao cliente externo, a empresa deverá ter uma atenção especial ao cliente interno, pois quem investe diretamente no funcionário está, na verdade, investindo diretamente no cliente (Monteiro, 2015). De acordo com Medeiros (2002), o principal objetivo da QVT é buscar o equilíbrio entre o indivíduo e a empresa, através de interações entre as exigências e as necessidades dos mesmos, fazendo com que os cargos se adaptem tanto aos indivíduos quanto à tecnologia da empresa, assim o trabalho passa a ser um caminho para a auto realização, o crescimento profissional, desenvolvimento das suas habilidades, proporcionando segurança e satisfação.

Recentemente, as empresas preocupam-se com as formas de ajudar o colaborador a possuir uma melhor qualidade de vida no trabalho, pois o mercado hoje está voltado para quem conseguir obter maior eficiência e eficácia no trabalho, isso sem causar danos à saúde dos seus colaboradores, pois são eles que realizam o processo produtivo (Ribeiro, 2012); assim a gestão da qualidade total nas organizações depende fundamentalmente do desenvolvimento do potencial humano, que é resultado do sentimento de bem estar que o funcionário sente trabalhando na empresa (Monteiro, 2015). 
Cada vez mais é necessário que o processo de comunicação seja de forma eficaz, pois todos os membros precisam ter acesso às informações no menor tempo possível, assim diversos setores conseguem agir de forma conjunta, ajudando a empresa a alcançar seus objetivos (Medeiros, 2002).

Na última década, no país, algumas organizações adaptam os modelos dos programas de qualidade de vida dos EUA, principalmente as multinacionais, demonstrando dados com redução nos gastos com assistência médica e em acidentes de trabalho, bem como um aumento da segurança, da saúde e do bem-estar dos seus colaboradores (Silva \& Lima, 2007).

Há pouco tempo, muitas empresas têm buscado incorporar programas padronizados de QVT, mas como não existe um padrão correto, e como uma empresa difere de outra, cada programa deve ter um direcionamento, através de um diagnóstico dos problemas e limitações dos seus recursos, tanto físicos quanto humanos, será possível fazer um planejamento adequado (Alves, 2011).

De acordo com Medeiros (2002), os trabalhadores nem sempre possuem satisfação em relação à segurança de emprego, a comunicação interna, desigualdade no tratamento, salário e condições físicas de trabalho. Além destes aspectos, Fernandes e Ferreira (2015) identificaram causas de mal estar no trabalho, dentre elas: a sobrecarga, a cobrança e a pressão na realização das atividades de trabalho, para que sejam melhorados.

Por outro lado, Ferreira, Leite e Mendes (2009) demonstraram alguns caminhos para a existência da QVT, no qual, pode-se destacar que os colaboradores que participam, opinam e discutem a Política de QVT, juntamente com algumas ações de QVT, contribuíram para uma melhora nas condições de trabalho dos colaboradores e na produtividade da empresa. Estes resultados abrem o espaço para a existência de diálogo no ambiente de trabalho.

$\mathrm{Na}$ implantação de um programa de QVT, é necessário buscar um modelo que se adapte, adequadamente, à situação em questão, existem diversos modelos para diagnosticar a QVT, devendo-se primeiro identificar quais aspectos age na qualidade de vida do colaborador, levando em consideração seu ambiente, cultura, valores, entre outros (Medeiros, 2002).

Espera-se assim, que as empresas objetivem benefícios sociais, incluindo ao mesmo tempo, maiores cuidados com o ambiente e que os trabalhadores possam desenvolver suas potencialidades, buscando integrar a vida no trabalho e a vida pessoal (Monteiro, 2015).

Menshhein (2007) relata que, é necessário saber conquistar o cliente interno, os colaboradores devem estar satisfeitos com a empresa agindo como um cliente, isso por acreditar no serviço ou produto da empresa em que está inserido e sentir-se parte importante no trabalho.

Com isto, as empresas atuais procuram valorizar os seus colaboradores resgatando sua qualidade pessoal, sua autoestima, motivação; levando em conta seus valores pessoais, possibilitando, assim, independência nas decisões; existe grande preocupação com o comportamento das pessoas, já que influenciam direta e indiretamente os objetivos das organizações (Silva \& Lima, 2007).

Na busca de avaliar a QVT, Willemann \& Ferreira (2018) constataram em um estudo com trabalhadores de uma empresa de transporte de Minas Gerais, que de forma geral, ocorre a 
QVT; entretanto, as maiores queixas dos trabalhadores foram inerentes à falta de diálogo, falta de crescimento e segurança no trabalho.

Conclui-se assim, que o ambiente de trabalho desempenha um papel importante para desenvolver uma harmonia entre trabalho e vida dos colaboradores, pois com apoio social, flexível e com boa gestão os colaboradores passam a trabalhar com harmonia, menos stress e conflito (Razak, Ma’amor, \& Hassan, 2016).

Portanto, os programas de QVT nas empresas contribuem para melhorar as condições de desenvolvimento das atividades, relacionamento com os colegas e assim reduz a taxa de rotatividade de funcionários e aumenta a satisfação dos mesmos; para a empresa aumenta seu desempenho, a produtividade, e o compromisso com os funcionários (Narehan, Hairunnisa, Norfadzillah, \& Freziamella, 2014).

Em pesquisa realizada por dos Santos e Borges (2018), verifica-se que os itens que apresentaram maior destaque são: que não há discriminação no seu local de trabalho e que existe insatisfação com os benefícios extras ofertados pela empresa e com os treinamentos que faz, assim observou-se que a satisfação com a vida possui relação com todas as dimensões da QVT, mas verificou-se também que não há diferença entre trabalhadores de diferentes idades, gêneros, tempo de atuação na empresa e caracterização da empresa, e que estes possuem uma leve percepção de sua QVT e Satisfação com a Vida.

\section{METODOLOGIA}

Para a coleta de dados, empregou-se um questionário estruturado, composto por 15 itens advindos do questionário para avaliação da qualidade de vida proposto por Ferro (2012). O referido instrumento contêm 78 itens; entretanto, para este estudo, utilizaram-se os 17 itens mais direcionados a qualidade de vida no trabalho. Para mensurar estes itens, utilizou-se uma escala Likert de 5 pontos: (1) discordo totalmente... (5) concordo totalmente. Buscou-se utilizar questões referentes aos dados de identificação do entrevistado, finalidade do trabalho, independência, relação com os colegas, retidão moral, reconhecimento, segurança no trabalho, carga de trabalho, a pesquisa foi quantitativa, descritiva, com dados primários através de questionário aplicado a uma amostra da população do município de Dom Pedrito.

O questionário foi elaborado na plataforma Google Forms, o qual foi disponibilizado um link em grupos de estudantes da faculdade Unipampa Dom Pedrito e na rede social dos pesquisadores. Após elaboração do instrumento de coletas, realizou-se um pré-teste no dia 22/01/2018, contando com a participação de três especialistas. Após o pré-teste, não se observou nenhuma questão a ser ajustada.

A pesquisa de campo foi realizada entre os dias 22/01/2018 e 29/01/2018, com uma amostra de 127 trabalhadores de Dom Pedrito. Este número é suficiente, já que Hair et al. (2009) recomenda 5 respondentes por questão; ou seja, a amostra mínima deveria ser 75 participantes. Cabe ressaltar que as pessoas residentes em outras cidades e que não trabalhavam foram excluídas da pesquisa. Em relação à técnica amostral, está é não probabilística e por conveniência, visto que foi conveniente convidar pessoas que fazem parte da vida pessoal e profissional dos pesquisadores. 
Após o encerramento da coleta dos dados, os mesmos foram importados ao programa SPSS, versão 20, a qual se analisou os resultados por meio de estatística descritiva, Teste-T e Anova. Os resultados são apresentados e discutidos a seguir.

\section{APRESENTAÇÃO DOS RESULTADOS}

Neste item serão apresentados e discutidos os resultados da pesquisa, iniciando pelo perfil dos respondentes.

\section{Tabela 1}

\section{Perfil da Amostra}

\begin{tabular}{l|c|c}
\hline Gênero & Frequência & Percentual \\
\hline Feminino & 72 & 56,7 \\
Masculino & 55 & 43,3 \\
\hline Total & $\mathbf{1 2 7}$ & $\mathbf{1 0 0 , 0}$ \\
\hline Faixa Etária & Frequência & Porcentagem \\
\hline Até 25 & 21 & 16,5 \\
$26-35$ & 29 & 22,8 \\
$36-45$ & 26 & 20,5 \\
$46-55$ & 25 & 19,7 \\
$56-65$ & 18 & 14,2 \\
Mais de 65 & 8 & 6,3 \\
\hline Total & $\mathbf{1 2 7}$ & $\mathbf{1 0 0 , 0}$ \\
\hline
\end{tabular}

Nota: dados da pesquisa.

A Tabela 1 apresenta o total de pesquisados divididos por gêneros e faixas etárias, na qual se verificou maior frequência de respondentes com idade entre 26 e 35 anos, em sua maioria do sexo feminino. A seguir serão investigados os itens relativos à QVT

Tabela 2

\section{Itens da QVT}

\begin{tabular}{l|c|c}
\multicolumn{1}{c|}{ Itens } & Média & Desvio Padrão \\
Não sofre preconceito no trabalho & 3,48 & 1,28 \\
Motivação para trabalhar & 3,41 & 1,35 \\
Falto pouco ao trabalho & 3,31 & 1,44 \\
Liberdade execução tarefas & 3,23 & 1,25 \\
Carga horária adequada & 3,20 & 1,31 \\
Comunicação adequada com chefes e colegas & 3,17 & 1,27
\end{tabular}


Colegas possuem disposição em ajudar

Não corro risco de vida

Reconhecimento pelo trabalho

Atividades proporcionam prazer

Não penso em mudar de emprego

Remuneração adequada

Ambiente adequado

Instrumentos de trabalho são suficientes

Não necessito mudar rotina de casa

Média
3,07

2,99

\begin{tabular}{|l|r}
3,07 & 1,26 \\
2,99 & 1,23 \\
2,96 & 1,34 \\
2,95 & 1,24 \\
2,95 & 1,31 \\
2,93 & 1,23 \\
2,85 & 1,31 \\
2,77 & 1,28 \\
2,77 & 1,35 \\
$\mathbf{3 , 0 7}$ & - \\
\hline
\end{tabular}

Nota: dados da pesquisa.

Conforme os resultados apresentados na Tabela 2, percebe-se que os itens "instrumentos de trabalho são suficientes para realização do trabalho" e "não necessito mudar a rotina de casa" são os que mais precisam de atenção por parte dos empregadores, pois receberam médias mais baixas, deve-se buscar avaliar como estão sendo disponibilizados e qual a quantidade dos materiais necessários para a realização do serviço, bem como a verificação de disponibilidade de horários diferenciados. $\mathrm{O}$ fato de haver instrumento de trabalho satisfatório vai ao encontro dos achados de Willemann \& Ferreira (2018), os quais destacaram existir falta de segurança no trabalho por parte de motoristas de empresas de transporte em Minas Gerais.

O que chama atenção também é o fato de as pessoas afirmarem que relativamente, que o trabalho faz com que elas mudem a rotina de casa. Embora

O item que apresentou melhor desempenho foi o fato de as pessoas não sofrerem preconceito. Este item refere-se às condições de trabalho, no qual, Willemann \& Ferreira (2018) constataram ser um importante fator, sendo em seus estudos, a assistência da empresa a funcionários foi percebida em seus estudos como o item mais relevante para um ambiente de trabalho salutar. Aqui, constata-se a existência de outro item relativo ao apoio na condição humana, visto que o preconceito é algo que atinge a dignidade pessoal.

As próximas Tabelas apresentaram uma comparação dos itens da QVT em relação ao gênero e faixa etária dos respondentes.

Tabela 3

Comparação entre os itens da QVT e o gênero

\begin{tabular}{l|c|c|c|c}
\hline \multicolumn{1}{c|}{ Itens } & Gênero & Média & Desvio Padrão & Significância* \\
\hline \multirow{2}{*}{ Falto pouco ao trabalho } & Feminino & 3,31 & 1,44 & \multirow{2}{*}{0,913} \\
& Masculino & 3,29 & 1,46 & \\
\hline \multirow{2}{*}{ Carga horária adequada } & Feminino & 3,12 & 1,20 & 0,477 \\
& Masculino & 3,30 & 1,44 & \\
\hline
\end{tabular}

UFAMBR, Manaus, v. 1, n.1, art. 2, pp. 18-35, janeiro-junho, 2019 http://www.periodicos.ufam.edu.br/ufambr 


\begin{tabular}{|c|c|c|c|c|}
\hline Motivação para trabalhar & $\begin{array}{l}\text { Feminino } \\
\text { Masculino }\end{array}$ & $\begin{array}{l}3,37 \\
3,47\end{array}$ & $\begin{array}{l}1,34 \\
1,38\end{array}$ & 0,691 \\
\hline Não sofre preconceito no trabalho & $\begin{array}{l}\text { Feminino } \\
\text { Masculino }\end{array}$ & $\begin{array}{l}3,40 \\
3,57\end{array}$ & $\begin{array}{l}1,28 \\
1,29\end{array}$ & 0,462 \\
\hline Não necessito mudar rotina de casa & $\begin{array}{l}\text { Feminino } \\
\text { Masculino }\end{array}$ & $\begin{array}{l}2,84 \\
2,66\end{array}$ & $\begin{array}{l}1,34 \\
1,37\end{array}$ & 0,463 \\
\hline Não penso em mudar de emprego & $\begin{array}{l}\text { Feminino } \\
\text { Masculino }\end{array}$ & $\begin{array}{l}2,81 \\
3,10\end{array}$ & $\begin{array}{l}1,22 \\
1,42\end{array}$ & 0,230 \\
\hline Remuneração adequada & $\begin{array}{l}\text { Feminino } \\
\text { Masculino }\end{array}$ & $\begin{array}{l}2,87 \\
3,01\end{array}$ & $\begin{array}{l}1,24 \\
1,22\end{array}$ & 0,518 \\
\hline Atividades proporcionam prazer & $\begin{array}{l}\text { Feminino } \\
\text { Masculino }\end{array}$ & $\begin{array}{l}2,84 \\
3,09\end{array}$ & $\begin{array}{l}1,24 \\
1,25\end{array}$ & 0,277 \\
\hline Ambiente adequado & $\begin{array}{l}\text { Feminino } \\
\text { Masculino }\end{array}$ & $\begin{array}{l}2,86 \\
2,83\end{array}$ & $\begin{array}{l}1,31 \\
1,33\end{array}$ & 0,917 \\
\hline Reconhecimento pelo trabalho & $\begin{array}{l}\text { Feminino } \\
\text { Masculino }\end{array}$ & $\begin{array}{l}3,06 \\
2,81\end{array}$ & $\begin{array}{l}1,36 \\
1,30\end{array}$ & 0,295 \\
\hline Colegas possuem disposição em ajudar & $\begin{array}{l}\text { Feminino } \\
\text { Masculino }\end{array}$ & $\begin{array}{l}3,05 \\
3,09\end{array}$ & $\begin{array}{l}1,14 \\
1,41\end{array}$ & 0,883 \\
\hline $\begin{array}{l}\text { Comunicação adequada com chefes e } \\
\text { colegas }\end{array}$ & $\begin{array}{l}\text { Feminino } \\
\text { Masculino }\end{array}$ & $\begin{array}{l}3,15 \\
3,20\end{array}$ & $\begin{array}{l}1,26 \\
1,29\end{array}$ & 0,837 \\
\hline $\begin{array}{l}\text { Instrumentos de trabalho são } \\
\text { suficientes }\end{array}$ & $\begin{array}{l}\text { Feminino } \\
\text { Masculino }\end{array}$ & $\begin{array}{l}2,98 \\
2,50\end{array}$ & $\begin{array}{l}1,24 \\
1,30\end{array}$ & $\mathbf{0 , 0 4 1}$ \\
\hline Liberdade execução tarefas & $\begin{array}{l}\text { Feminino } \\
\text { Masculino }\end{array}$ & $\begin{array}{l}3,18 \\
3,29\end{array}$ & $\begin{array}{l}1,27 \\
1,24\end{array}$ & 0,624 \\
\hline Não corro risco de vida & $\begin{array}{l}\text { Feminino } \\
\text { Masculino }\end{array}$ & $\begin{array}{l}3,18 \\
2,74\end{array}$ & $\begin{array}{l}1,23 \\
1,20\end{array}$ & $\mathbf{0 , 0 4 9}$ \\
\hline
\end{tabular}

Nota: dados da pesquisa.

* Técnica adotada: Teste-T

Na Tabela 3 vê-se que os itens "corro risco de vida" e "instrumentos de trabalho são suficientes" são os que receberam maior variação, isto é, tiveram valores diferentes para

UFAMBR, Manaus, v. 1, n.1, art. 2, pp. 18-35, janeiro-junho, 2019 http://www.periodicos.ufam.edu.br/ufambr 
mulheres e para homens. Estes resultados fazem certo sentido, visto que de maneira geral, homens atuam mais em atividades braçais e correm mais risco, por atuarem desta forma e de maneira geral, viajam mais.

Tabela 4

Comparação entre os itens e a faixa etária

\begin{tabular}{|c|c|c|c|c|}
\hline Item & Faixa etária & Média & Desvio Padrão & Significância* \\
\hline \multirow{3}{*}{ Falto pouco ao trabalho } & Até 35 & 3,28 & 1,5913 & \multirow{3}{*}{0,752} \\
\hline & $36-55$ & 3,41 & 1,32 & \\
\hline & 56 ou mais & 3,15 & 1,40 & \\
\hline \multirow{3}{*}{ Carga horária adequada } & Até 35 & 3,25 & 1,24 & \multirow{3}{*}{0,043} \\
\hline & $36-55$ & 3,44 & 1,26 & \\
\hline & 56 ou mais & 2,65 & 1,41 & \\
\hline \multirow{3}{*}{ Motivação para trabalhar } & Até 35 & 3,48 & 1,48 & \multirow{3}{*}{0,813} \\
\hline & $36-55$ & 3,43 & 1,25 & \\
\hline & 56 ou mais & 3,26 & 1,34 & \\
\hline \multirow{3}{*}{ Não sofre preconceito no trabalho } & Até 35 & 3,8 & 1,29 & \multirow{3}{*}{$\mathbf{0 , 0 2 3}$} \\
\hline & $36-55$ & 3,42 & 1,23 & \\
\hline & 56 ou mais & 2,96 & 1,24 & \\
\hline \multirow{3}{*}{ Não necessito mudar rotina de casa } & Até 35 & 3,2 & 1,29 & \multirow{3}{*}{$\mathbf{0 , 0 1 8}$} \\
\hline & $36-55$ & 2,4 & 1,24 & \\
\hline & 56 ou mais & 2,7 & 1,51 & \\
\hline \multirow{3}{*}{ Não penso em mudar de emprego } & Até 35 & 2,94 & 1,37 & \multirow{3}{*}{0,699} \\
\hline & $36-55$ & 3,03 & 1,31 & \\
\hline & 56 ou mais & 2,76 & 1,24 & \\
\hline \multirow{3}{*}{ Remuneração adequada } & Até 35 & 3,16 & 1,09 & \multirow{3}{*}{0,204} \\
\hline & $36-55$ & 2,86 & 1,35 & \\
\hline & 56 ou mais & 2,65 & 1,19 & \\
\hline \multirow{3}{*}{ Atividades proporcionam prazer } & Até 35 & 3,14 & 1,21 & \multirow{3}{*}{0,357} \\
\hline & $36-55$ & 2,78 & 1,33 & \\
\hline & 56 ou mais & 2,92 & 1,12 & \\
\hline \multirow{3}{*}{ Ambiente adequado } & Até 35 & 2,96 & 1,39 & \multirow{3}{*}{0,693} \\
\hline & $36-55$ & 2,82 & 1,32 & \\
\hline & 56 ou mais & 2,69 & 1,15 & \\
\hline \multirow{3}{*}{ Reconhecimento pelo trabalho } & Até 35 & 2,88 & 1,36 & \multirow{3}{*}{0,64} \\
\hline & $36-55$ & 3,09 & 1,25 & \\
\hline & 56 ou mais & 2,84 & 1,48 & \\
\hline \multirow{3}{*}{ Colegas possuem disposição em ajudar } & Até 35 & 3,20 & 1,20 & \multirow{3}{*}{0,363} \\
\hline & $36-55$ & 3,09 & 1,17 & \\
\hline & 56 ou mais & 2,76 & 1,53 & \\
\hline \multirow{3}{*}{$\begin{array}{l}\text { Comunicação adequada com chefes e } \\
\text { colegas }\end{array}$} & Até 35 & 3,44 & 1,28 & \multirow{3}{*}{0,104} \\
\hline & $36-55$ & 3,09 & 1,25 & \\
\hline & 56 ou mais & 2,80 & 1,23 & \\
\hline \multirow{2}{*}{ Instrumentos de trabalho são suficientes } & Até 35 & 2,83 & 1,41 & \multirow{2}{*}{0,377} \\
\hline & $36-55$ & 2,87 & 1,23 & \\
\hline
\end{tabular}

UFAMBR, Manaus, v. 1, n.1, art. 2, pp. 18-35, janeiro-junho, 2019 http://www.periodicos.ufam.edu.br/ufambr 


\begin{tabular}{l|c|c|c|c} 
& 56 ou mais & 2,46 & 1,10 & \\
\hline \multirow{2}{*}{ Liberdade execução tarefas } & Até 35 & 3,42 & 1,26 & \\
& $36-55$ & 3,33 & 1,14 & $\mathbf{0 , 0 2 9}$ \\
& 56 ou mais & 2,65 & 1,32 & \\
\hline \multirow{3}{*}{ Não corro risco de vida } & Até 35 & 3,18 & 1,30 & \\
& $36-55$ & 2,90 & 1,20 & 0,371 \\
\hline
\end{tabular}

Nota: dados da pesquisa

* Técnica adotada: Anova

Conforme a Tabela 4, constata-se que existem diferença nos itens: "não sofro preconceito em meu trabalho", "carga horária adequada", "liberdade na execução das tarefas" e "não preciso mudar minha rotina de casa. Analisando a faixa etárias da pessoas, observa-se que trabalhadores mais jovens, possuem mais liberdade para trabalhar e mudam menos a sua rotina. Por outro lado, sofrem mais preconceito. Os trabalhadores de meia idade, acreditam ter uma carga horária mais adequada; mas, possuem sua rotina mais alterada. Por fim, os trabalhadores de mais idade, sofrem menos preconceito; mas por outro lado, apresentam uma pior carga horária e uma menor liberdade para a realização de atividades.

Por fim, observou-se a diferença da QVT entre o perfil da amostra. Estes resultados podem ser analisados na Tabela 5.

Tabela 5

Comparação entre a QVT e o perfil da amostra

\begin{tabular}{l|c|c|c|c}
\hline Perfil da Amostra & Variável & Média & Desvio Padrão & Significância \\
\hline Gênero* $^{*}$ & Feminino & 3,05 & 0,79 & 0,76 \\
\hline & Masculino & 3,10 & 0,78 & 0,88 \\
Faixa etária** & Até 35 & 3,30 & 0,66 & 0,94 \\
& $36-55$ & 2,69 & 0,69 & \\
\hline
\end{tabular}

Nota: dados da pesquisa.

* Técnica adotada: Teste-T

** Técnica adotada: Anova

Pode-se observar, conforme a Tabela 5, que não há influência entre os gêneros dos respondentes e os itens da pesquisa QVT, e também não há importância entre as diferentes faixas etárias e os itens da pesquisa, pelo fato da significância ser acima de 0,05, o que corrobora os achados da pesquisa realizada por dos Santos e Borges (2018), demonstrando que há o mesmo nível de QVT independente do gênero ou da faixa etária do trabalhador.

Talvez, os programas de QVT têm contribuído para que de fato, haja a uniformidade da percepção dos mesmos, conforme sugerido por Alves (2011); ou até mesmo, a ausência destes programas faça com que as pessoas tenham uma percepção igual.

\section{CONSIDERAÇÕES FINAIS}

O Programa QVT se constitui de ações das empresas visando facilitar e satisfazer às necessidades dos seus colaboradores, no que tange os aspectos profissionais e também os pessoais, assim a elaboração e execução de benefícios melhora progressivamente a qualidade

UFAMBR, Manaus, v. 1, n.1, art. 2, pp. 18-35, janeiro-junho, 2019 http://www.periodicos.ufam.edu.br/ufambr 
do ambiente organizacional, e uma maior motivação dessas pessoas no trabalho está inteiramente ligada a sua satisfação com a empresa.

O presente trabalho teve por objetivo principal descobrir o nível de QVT da população de Dom Pedrito/RS. Constatou-se a existência de um nível de QVT intermediário. Este resultado sugere que a QVT não é algo desprezível, mas por outro lado, ainda não destacado pelos participantes do estudo. Cabe ressaltar, que a pesquisa foi realizada em uma pequena cidade do interior do Rio Grande do Sul, com características fronteiriças, o que pode tornar este resultado singular. Conforme já destacado por Gao e Long (2014) e You (2018), pequenas cidades de fronteira possuem um fluxo de pessoas diferenciadas, e isto, pode influenciar na cultura local.

Sobre a diferença de percepção de QVT, não se constatou diferenças de níveis entre gênero e faixa etária, sugerindo que a QVT tende a ser a mesma, corroborando com os achados de da Silva e Borges (2018). Cabe ressaltar, que a pesquisa não foi realizada em uma empresa específica; portanto, é possível que alguns trabalhadores tenham recebido alguma ação de QVT e outros não; já que, nem todas as empresas adotam e se preocupam com a QVT, mesmo sendo esta, uma recomendação da literatura.

Em relação aos itens da QVT, a inexistência de preconceitos e a motivação para o trabalho foram os mais destacados. Isto é um resultado positivo, já que, o preconceito é algo cada vez mais reprimido socialmente; e a motivação, é o que as empresas buscam, por parte dos seus trabalhadores. Sobre os itens mais negativos, verificou-se um geral descontentamento com os instrumentos de trabalho não são satisfatórios e há uma mudança na rotina. Este resultado pode ser característico de uma cidade pequena, na qual, tende a ter mais instrumentos de trabalho não tão sofisticados e a mudança na rotina, seja algo menos cotidiano, na ótica destas pessoas, vendo o trabalho, como algo separado à sua vida pessoal.

Por fim, ainda em relação aos itens da QVT, percebeu-se que trabalhadores mais jovens, possuem mais liberdade para trabalhar e mudam menos a sua rotina. Por outro lado, sofrem mais preconceito. Os trabalhadores de meia idade acreditam ter uma carga horária mais adequada; mas, possuem sua rotina mais alterada. Por fim, os trabalhadores de mais idade, sofrem menos preconceito; mas por outro lado, apresentam uma pior carga horária e uma menor liberdade para a realização de atividades.

Percebe-se assim, que as pessoas mais jovens possuem mais liberdade e ao mesmo tempo, têm maior preconceito; já as de mais idade, ao contrário, possuem menos liberdade e um menor preconceito. Teoricamente, observa-se um resultado antagônico, visto que em tese, se dá mais liberdade para quem não se tem preconceito.

A principal limitação deste trabalho é o fato da amostra ser não probabilística e o estudo ter sido realizado pela internet, inviabilizando quem não teve acesso à internet no período da pesquisa. Como recomendação de pesquisa, sugerem-se estudos similares em cidades maiores, no sentido de verificar se o nível de QVT também é regular. Propõem-se ainda, estudos que busquem verificar por que pode ocorrer preconceito no trabalho e ao mesmo tempo, há uma maior liberdade na execução de tarefas. 


\section{REFERÊNCIAS}

Alves, E. F. (2011). Programas e ações em qualidade de vida no trabalho: possibilidades e limites das organizações. Revista Eletrônica Fafit/Facic, 2(1).

Andrade, R. M. (2012). Qualidade de vida no trabalho dos colaboradores da empresa Farben S/A indústria química (Monografia de pós-graduação). Universidade do Extremo Sul Catarinense, Criciúma, SC, Brasil.

Andrade, S. M. D. (2016). Qualidade de vida no trabalho: proposta de um modelo integrador do BPSO com justiça organizacional para o bem-estar de servidores públicos (Doctoral dissertation). Universidade de São Paulo, SP, Brasil.

Carvalho, J. F., Martins, E. P. T., Lúcio, L., \& Papandréa, P. J. (2013). Qualidade de vida no trabalho e fatores motivacionais dos colaboradores nas organizações. Educação em foco, $7(1), 21-23$.

da Silva Timossi, L., de Francisco, A. C., dos Santos Junior, G., \& de Paula Xavier, A. A. (2010). Análise da qualidade de vida no trabalho de colaboradores com diferentes níveis de instrução através de uma análise de correlações. Production, 20(3), 471-480.

da Silva, A. C. C. J., Furtado, J. H., \& Zanini, R. R. (2015). Um estudo sobre a qualidade de vida no trabalho (QVT) e os fatores associados. Iberoamerican Journal of Industrial Engineering, 7(14), 182-200.

dos Santos, P. S., \& Borges, G. R. (2018). A influência da satisfação e qualidade de vida no trabalho entre alunos do curso de agronegócio. Revista de Carreiras e Pessoas (ReCaPe). ISSN 2237-1427, 8(3).

Fernandes, E. C. (1996). Qualidade de vida no trabalho: como medir para melhorar. Salvador: Casa da Qualidade.

Fernandes, L. C., \& Ferreira, M. C. (2015). Qualidade de vida no trabalho e risco de adoecimento: estudo no poder judiciário brasileiro. Psicologia USP, 26(2), 296-306.

Ferreira, M. C., Leite, J. V., \& Mendes, A. M. (2009). Mudando a gestão da qualidade de vida no trabalho. Revista Psicologia: Organizações e Trabalho, 9(2), 109-123.

Ferro, F. F. (2012). Instrumentos para medir a qualidade de vida no trabalho e a ESF: Uma revisão de literatura (Monografia de pós-graduação). Universidade Federal de Minas Gerais, Brumadinho, MG, Brasil.

Figueiredo, V. D. M. (2008). Pequenos municípios e pequenas cidades do estado do Rio Grande do Sul: contrastes, perfil do desenvolvimento e de qualidade de vida, 1980-2000.

França, A. C. L. (1996). Indicadores empresariais de qualidade de vida no trabalho: esforço empresarial e satisfação dos empregados no ambiente de manufaturas com certificação ISO 9000 (Doctoral dissertation). Universidade de São Paulo, SP, Brasil.

Gao, X., \& Long, C. X. (2014). Cultural border, administrative border, and regional economic development: Evidence from Chinese cities. China Economic Review, 31, 247-264. 
Hair, J. F., Black, W. C., Babin, B. J., Anderson, R. E., \& Tatham, R. L. (2009). Análise multivariada de dados. Bookman Editora.

Liberato, H. L., Ballstaedt, E. H., \& Abril, J. D. C. J. (2013). Estresse no trabalho. (Monografia de pós-graduação). Associação Catarinense De Medicina, Universidade Federal De Santa Catarina - Ufsc, SC, Brasil.

Medeiros, E. G. (2002). Análise da Qualidade de Vida no Trabalho: um estudo de caso na área da construção civil (Dissertação de mestrado). Universidade Federal do Rio Grande do Sul, Porto Alegre, RS, Brasil.

Menshhein, R. M. (2007). Marketing Interno. São Paulo: Atlas.

Minayo, M. C. D. S., Hartz, Z. M. D. A., \& Buss, P. M. (2000). Quality of life and health: a necessary debate. Ciência \& Saúde Coletiva, 5(1), 7-18.

Miranda, C. (2009). O Desafio em manter funcionários motivados: Os Fatores Motivacionais para o Trabalho (Monografia de Graduação). ESAB-Escola Superior Aberta do Brasil, Vila Velha, ES, Brasil.

Monteiro, G. M. S. (2015). Qualidade de vida no trabalho: o estudo de caso no setor de serviços de limpeza, copa e cozinha da UNIJUÍ - Câmpus Santa Rosa (Trabalho de conclusão de curso). Universidade Regional do Noroeste do Estado do Rio Grande do Sul - UNIJUÍ, RS, Brasil.

Nahas, M. V. (2006). Atividade física, saúde e qualidade de vida: conceitos e sugestões para um estilo de vida ativo. 4. ed. Londrina: Midiograf.

Narehan, H., Hairunnisa, M., Norfadzillah, R. A., \& Freziamella, L. (2014). The effect of quality of work life (QWL) programs on quality of life (QOL) among employees at multinational companies in Malaysia. Procedia-Social and Behavioral Sciences, 112, 2434.

Pereira, D. L. (2011). Qualidade de vida no trabalho: influências dos avanços tecnológicos (Monografia de pós-graduação). Universidade Tecnológica Federal do Paraná, Ponta Grossa, PR, Brasil.

Razak, N. A., Ma'amor, H., \& Hassan, N. (2016). Measuring reliability and validity instruments of work environment towards quality work life. Procedia Economics and Finance, 37, 520-528.

Ribeiro, C. A. O., \& Campos, L. N. M. (2012). Qualidade de vida no trabalho http://dx. doi. org/10.15601/1983-7631/rt. v2n2p28-39. Revista Tecer, 2(2).

Ribeiro, L. A., \& SANTANA, L. C. D. (2015). Qualidade de vida no trabalho: fator decisivo para o sucesso organizacional. Revista de Iniciação Científica - RIC Cairu, 2(02), 75-96.

Rodrigues, M. V. C. (1994). Qualidade de vida no trabalho. RJ: Vozes. 
Santos, D. F. A. D. (2013). Qualidade de Vida no Trabalho: um estudo sobre a percepção dos funcionários do Centro Estadual de Ensino Fundamental Tucunduva (Trabalho de conclusão de curso). Universidade Regional do Noroeste do Estado do Rio Grande do Sul - UNIJUÍ, RS, Brasil.

Silva, N., \& Lima, M. (2007). Qualidade de vida no trabalho: o estudo qualitativo na empresa natura. Semana Científica e Cultural do Serviço Social das Faculdades Unificadas da Fundação Educacional de Barretos, 5.

Veiga, A. (2000). Tempos modernos. Revista Veja. São Paulo: Editora, Abril.

Vieira, M. L., Lacerda, A. L. R., Vieira, M. C., \& Seidl-de-Moura, M. L. (2011). Características sociodemográficas e aspectos psicossociais de famílias brasileiras residentes em capitais e cidades pequenas do interior. Barbarói, (34), 60-79.

Willemann, A. C., \& Ferreira, A. C. (2018). Qualidade de Vida no Trabalho em uma Empresa de Transporte de Passageiros e Fretamento do Alto Paranaíba-MG. Qualitas Revista Eletrônica, 18(3), 88-112. 